\title{
Understanding the Gaps in Obesity Management in the UAE: Perceptions, Barriers, and Attitudes
}

\author{
Rita Nawara Elamin Ibrahim ${ }^{b}$ Salah Abusnanac Fatheya Al Awadi ${ }^{b}$ \\ Fatema Hasan Al Hammadi $^{d}$ Mohamed Farghaly Tarek M. Fiad $^{\mathrm{f}}$ Hazem Aly $^{\mathrm{g}}$ \\ Yasmin Aly Mohamed $^{9}$ Zainab Ben Serghin ${ }^{9}$

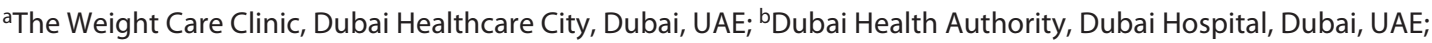 \\ 'Diabetes and Endocrinology Department, University of Sharjah, Sharjah, UAE; dObesity Clinic, Sheikh Khalifa \\ Medical City, Abu Dhabi, UAE; ${ }^{e}$ Dubai Medical College, Dubai, UAE; ${ }^{f}$ Center for Diabetes and Endocrinology, Sheikh \\ Khalifa Medical City, Abu Dhabi, UAE; ${ }^{9}$ Novo Nordisk Pharmaceutical Co., Dubai, UAE
}

\section{Keywords}

The Awareness, Care, and Treatment in Obesity management-International Observation · Obesity · Obesity management · Perceptions · United Arab Emirates

\begin{abstract}
Introduction: Obesity is a chronic relapsing disease of which, globally, the prevalence has reached epidemic proportions. The ACTION-IO study (NCT03584191) investigated the perceptions, attitudes, and behaviors of people with obesity (PwO) and healthcare professionals (HCPs), which can help in devising strategies for its optimal management. Here, we present the results from the United Arab Emirates (UAE). Methods: The ACTION-IO study was a cross-sectional study conducted in 11 countries, including the UAE, that collected data via a survey. Eligible UAE PwO were $\geq 18$ years with a BMI of $\geq 30 \mathrm{~kg} / \mathrm{m}^{2}$ (self-reported height and weight). Eligible HCPs were in direct patient care. Data were collected in the UAE between July 11, 2018, and September 5, 2018. Results: A total of 750 PwO and 200 HCPs completed the survey in the UAE. Both PwO (82\%) and HCPs (78\%) acknowledged obesity as a chronic disease and agreed that it has a large
\end{abstract}

impact on overall health (PwO 88\% and HCPs 80\%). More HCPs felt that diabetes and stroke (both 91\%) had a larger impact on overall health than did obesity. Many PwO (76\%) assumed full responsibility for their weight loss; $84 \%$ of HCPs acknowledged responsibility for actively contributing to patient weight loss efforts. The top motivator for weight loss among PwO was wanting to be more fit/in better shape (45\%), while HCPs believed the main motivator was general health concerns (83\%). The top barrier against initiating weight management discussions provided by HCPs was that they felt PwO were not interested in losing weight (69\%), whereas only $10 \%$ of PwO selected this response. The mean delay between struggling with excess weight and having a weight management discussion with an HCP was 4 years. Discussion/Conclusion: These UAE results highlight differences in the perceptions and attitudes toward obesity from PwO and HCPs and reflect a need to understand weight management concerns to initiate earlier and more effective PwO-HCP conversations. The findings will inform educational needs on the biological basis of obesity and its clinical management and will help to address regional barriers for effective obesity care.

(c) 2021 The Author(s).

Published by S. Karger AG, Basel karger@karger.com www.karger.com/dde

Karger $\stackrel{\text { ' }}{5}$

BOPEN ACCESS
(C) 2021 The Author(s)

Published by S. Karger AG, Basel

This article is licensed under the Creative Commons AttributionNonCommercial-NoDerivatives 4.0 International License (CC BY NC-ND) (http://www.karger.com/Services/OpenAccessLicense) Usage and distribution for commercial purposes as well as any distribution of modified material requires written permission.
Correspondence to:

Rita Nawar, rita.nawar@gmail.com 


\section{Introduction}

Obesity is a chronic, relapsing disease that has a significant impact on overall health and quality of life [1]. It is associated with several medical conditions including certain cancers, cardiovascular disease, diabetes, and musculoskeletal disorders [1-3], and people with obesity $(\mathrm{PwO})$ are at an increased risk of serious complications from COVID-19 infection [4-7]. Obesity is also linked to a reduced life expectancy [8] and a low health-related quality of life [9-11]. The etiology of obesity is multifactorial; many factors including genetic, epigenetic, physiological, environmental, and sociocultural contribute to the pathogenesis of obesity $[1,12,13]$. Evidence is accumulating to also indicate sleep deprivation, gut microbiota dysbiosis, and psychological stress, among others, as contributors to obesity [13-15].

Obesity has become a global epidemic; as of 2016, around 650 million adults aged $\geq 18$ were considered to have obesity [16]. In particular, prevalence of overweight and obesity is suggested to have at least doubled in the United Arab Emirates (UAE) between 1989 and 2017 [17]. This increase in prevalence of obesity is thought to be correlated to the rapid development and economic growth seen in the Gulf countries [18]. The UAE has an obesity prevalence rate of $31.7 \%$, per the Central Intelligence Agency World Factbook, and the Gulf countries are ranked among the top 40 countries in the world for high prevalence in obesity rate [19].

Despite the chronic nature and long-term implications of obesity, practice recommendations and guidelines are not widely followed in primary care [20]. Only a small percentage of $\mathrm{PwO}$ are receiving the recommended lifestyle, surgical and/or pharmacological treatment [21]. Barriers for optimal management of obesity include misperceptions about the disease, insufficient training of healthcare professionals (HCPs), and variable care not conforming to evidence-based guidelines [21, 22]. Understanding the perceptions and behaviors of $\mathrm{PwO}$ and HCPs could facilitate devising strategies for optimal disease management [22].

The Awareness, Care, and Treatment in Obesity maNagement-International Observation (ACTION-IO) study examined obesity-related perceptions, attitudes, and behaviors among $\mathrm{PwO}$ and HCPs, and revealed the need to increase understanding in obesity to improve education concerning its physiological basis and clinical management [23]. This study reports results of the ACTION-IO study in the UAE, which could help address regional barriers to effective obesity treatment and management. The study also aims to generate insights to guide collaborative action to improve care, education, and support for PwO. The study is a step toward creating a communication platform to help change how HCPs manage, treat, and support obesity care.

\section{Methods}

\section{Study Design and Participants}

Full methodology for the ACTION-IO survey has been reported previously [23]. The UAE-specific details have been provided below. The ACTION-IO study was a cross-sectional, noninterventional, descriptive study (NCT03584191) that collected data via an online survey conducted by a third-party vendor (KJT Group, Honeoye Falls, NY, USA), utilizing existing databases/panels in the UAE between July 11, 2018, and September 5, 2018. The study and survey instruments were approved by the Dubai Healthcare City Authority-Regulation/Research Ethics Review Committee. The study, sponsored by Novo Nordisk, complied with all laws and regulations regarding management of personal information in the UAE and was conducted in accordance with the Guidelines for Good Pharmacoepidemiology Practices [24], and in accordance with the Declaration of Helsinki [25].

All respondents provided electronic informed consent prior to initiation of the survey screening questions that determined eligibility. To achieve a nationally representative sample for the UAE, the PwO sample was targeted based on age, ethnicity, gender, household income, education, and region. The HCP sample was monitored for specialist types. Eligible PwO were aged at least 18 years, residents of UAE, not pregnant, and did not participate in intense fitness or body building programs. People who had experienced significant, unintentional weight loss during the last 6 months were excluded. Eligible HCPs were medical practitioners in the UAE who had been in practice for 2 years or more, with at least $70 \%$ of their time involved in direct patient care and who had seen 100 or more patients during the last month, at least 10 of whom had a BMI of at least $30 \mathrm{~kg} / \mathrm{m}^{2}$. HCPs specializing in general, plastic, or bariatric surgery were excluded. All individuals could access the first part of the survey, and an initial set of screening questions determined eligibility. UAE PwO qualified for the full survey if they met the required demographic targets, had a BMI of at least $30 \mathrm{~kg} /$ $\mathrm{m}^{2}$ from their self-reported height and weight, and met the other eligibility requirements. Demographic targets were monitored throughout data collection to ensure population representativeness.

\section{Survey Development and Pretesting}

Two questionnaires (one each for $\mathrm{PwO}$ and HCPs, respectively) were developed by the study steering committee, which comprised international obesity experts (including those in primary care, medical specialties, and psychology) from countries participating in the ACTION-IO study and 3 medical doctors employed by the sponsor, Novo Nordisk. The surveys were developed using the ACTION US [21] and ACTION Canada [22] studies as a starting point and then modified with insights from the steering committee. The surveys were offered both in English and Arabic. Web-assisted pretests of 60 min were conducted with $4 \mathrm{PwO}$ and $4 \mathrm{HCPs}$; UAE pretest participants took the survey online while speaking with a moderator by telephone or in-person. This was to assess clarity, face validity, and relevance of the questions. Surveys were designed to facilitate comparisons within and across respondent types.
38

Dubai Diabetes Endocrinol J 2021;27:37-49 DOI: $10.1159 / 000514359$
Nawar et al. 
Table 1. Respondent demographics and characteristics

\begin{tabular}{|c|c|c|}
\hline & $\begin{array}{l}\mathrm{PwO} \\
(n=750)\end{array}$ & $\begin{array}{l}\text { HCPs } \\
(n=200)\end{array}$ \\
\hline Age, years (range) & $35(18-67)$ & $44(28-74)$ \\
\hline \multicolumn{3}{|l|}{ Gender } \\
\hline Male & $573(76)$ & $132(66)$ \\
\hline Female & $177(24)$ & $68(34)$ \\
\hline \multicolumn{3}{|l|}{ BMI classification $^{\text {a }}$} \\
\hline Respondents & $750(100)$ & $107(54)$ \\
\hline Underweight or healthy range $\left(<25 \mathrm{~kg} / \mathrm{m}^{2}\right)$ & - & $42(39)$ \\
\hline Overweight $\left(25-29.9 \mathrm{~kg} / \mathrm{m}^{2}\right)$ & - & $52(49)$ \\
\hline Obesity class I $\left(30-34.9 \mathrm{~kg} / \mathrm{m}^{2}\right)$ & $303(40)$ & $13(12)$ \\
\hline Obesity class II $\left(35-39.9 \mathrm{~kg} / \mathrm{m}^{2}\right)$ & $236(32)$ & - \\
\hline Obesity class III $\left(\geq 40 \mathrm{~kg} / \mathrm{m}^{2}\right)$ & $211(28)$ & - \\
\hline \multicolumn{3}{|l|}{ Comorbidities $^{\mathrm{a}}$} \\
\hline 0 & $433(58)$ & \\
\hline 1 & $122(16)$ & \\
\hline 2 & $40(5)$ & \\
\hline 3 & $26(3)$ & \\
\hline$\geq 4$ & $129(17)$ & \\
\hline \multicolumn{3}{|l|}{$\mathrm{HCP}$ category } \\
\hline PCP & & $100(50)$ \\
\hline General practice & & $38(19)$ \\
\hline Family practice & & $31(16)$ \\
\hline Internal medicine & & $31(16)$ \\
\hline Specialist & & $100(50)$ \\
\hline Diabetologist/endocrinologist & & $37(19)$ \\
\hline Internal medicine (non-PCP) & & $22(11)$ \\
\hline Gastroenterologist & & $41(21)$ \\
\hline \multicolumn{3}{|l|}{ Obesity specialist $\mathrm{t}^{\mathrm{b}}$} \\
\hline Yes & & $138(69)$ \\
\hline No & & $62(31)$ \\
\hline
\end{tabular}

Data provided are $n(\%)$, except for age. HCP, healthcare professional; PCP, primary care physician; $\mathrm{PwO}$, people with obesity. ${ }^{a} \mathrm{PwO}$ data represent weighted percentages. All other data in the table represent the final unweighted dataset. ${ }^{b}$ HCPs who cite themselves as experts in obesity/weight loss management or work in obesity service clinics or see $\geq 50 \%$ of their patients for obesity/weight management or have advanced/formal training in treatment of obesity/weight management beyond medical school.

\section{Outcomes}

Outcomes were measured by multiple-item selection, numeric response, single-item selection, end-anchored 5-point Likert agreement scales, fully anchored 5-point Likert scales, and by ranking. For details, please refer to the global ACTION-IO study [23].

\section{Analysis}

Analysis of de-identified data was conducted by KJT Group using SPSS (IBM, version 23.0), Stata (StataCorp LLC, version IC 14.2), and Excel (Microsoft, version 2016). Data were summarized using univariate descriptive statistics (means, medians, and frequencies). Only data from those who completed the survey were included in the analyses.

Understanding the Gaps in Obesity

Management in the UAE

\section{Results}

\section{Participants}

A total of 10,038 $\mathrm{PwO}$ and $493 \mathrm{HCPs}$ were invited to the study, with a response rate of $30.4 \%$ and $99.8 \%$, respectively. The survey was successfully completed by $750 \mathrm{PwO}$ and $200 \mathrm{HCPs}$. The average completion time of the survey was $24 \mathrm{~min}$ for $\mathrm{PwO}$ and $36 \mathrm{~min}$ for HCPs. The mean age of $\mathrm{PwO}$ respondents was 35 years; $76 \%$ were male, and $42 \%$ had at least 1 comorbidity, as shown in Table 1 . The mean age of HCP respondents was 44 years; $66 \%$ were male, and 50\% were primary care physicians.

Dubai Diabetes Endocrinol J 2021;27:37-49 


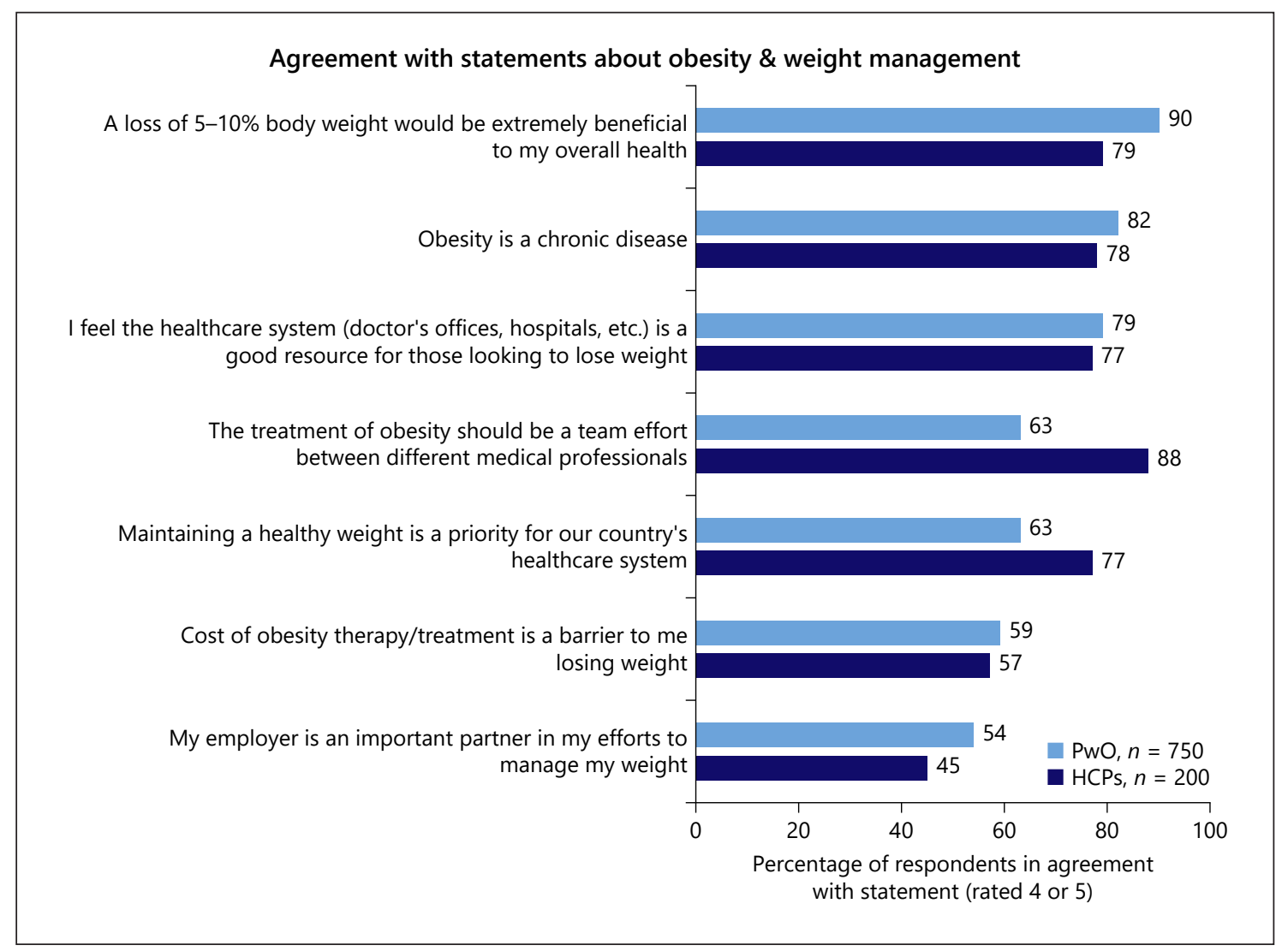

Fig. 1. Perception of obesity and weight management by UAE PwO and HCPs. Rated on a scale where 1 means "Do not agree at all" and 5 means "Completely agree." HCP, healthcare professional; PwO, people with obesity.

\section{Perceptions of Obesity}

The majority of PwO (68\%) felt that they had obesity, while $6 \%$ felt that they had extreme obesity, $23 \%$ felt that they had overweight, and $2 \%$ felt that they had normal weight. Most $\mathrm{PwO}(82 \%)$ and HCPs (78\%) agreed that obesity is a chronic disease. Weight loss of $5-10 \%$ body weight was considered beneficial to the overall health of PwO by $90 \%$ of $\mathrm{PwO}$ and $79 \%$ of HCPs, as shown in Figure 1. Both $\mathrm{PwO}(88 \%)$ and HCPs (80\%) agreed that obesity had a large impact on overall health, as shown in Figure 2. In comparison, $74-80 \%$ of $\mathrm{PwO}$ and $75-91 \%$ of HCPs believed that stroke, diabetes, cancer, and chronic obstructive pulmonary disease had a large impact on overall health.

\section{Weight Loss Attempts, Outcomes, and Barriers}

Many PwO (76\%) believed that losing weight was fully their responsibility, while $84 \%$ of HCPs acknowledged that HCPs had a responsibility to help $\mathrm{PwO}$ achieve weight loss successfully. A large proportion of $\mathrm{PwO}$
(73\%) and HCPs (55\%) believed that $\mathrm{PwO}$ could lose weight if they set their mind to it (Fig. 3); however, many $\mathrm{PwO}$ struggled to achieve long-term weight loss (see below). The most important weight management goal for PwO to personally achieve was to improve their appearance (48\%). Nearly all PwO (89\%) stated that they had made at least 1 serious weight loss effort in the past. A mean of 5 weight loss attempts were made by $\mathrm{PwO}$, of whom $49 \%$ regained weight after a successful weight loss effort. Out of the $32 \%$ of $\mathrm{PwO}$ who achieved weight loss of $\geq 5 \%$ body mass over the last 3 years, $29 \%$ sustained the weight loss for $\geq 1$ year ( $9 \%$ of total $\mathrm{PwO}$ ). For those who had a weight management discussion with an HCP, there was a mean delay in time of 4 years between $\mathrm{PwO}$ starting to struggle with excess weight or obesity and having the discussion with an HCP, as shown in Figure 4a. Initial difficulties with weight management started at a mean age of 27 years (shown in Fig. 4b) and a weight management conversation with an HCP occurred when PwO were at a mean age of 32 years (Fig. 4c). Both $\mathrm{PwO}$ and
40

Dubai Diabetes Endocrinol J 2021;27:37-49 DOI: $10.1159 / 000514359$
Nawar et al. 


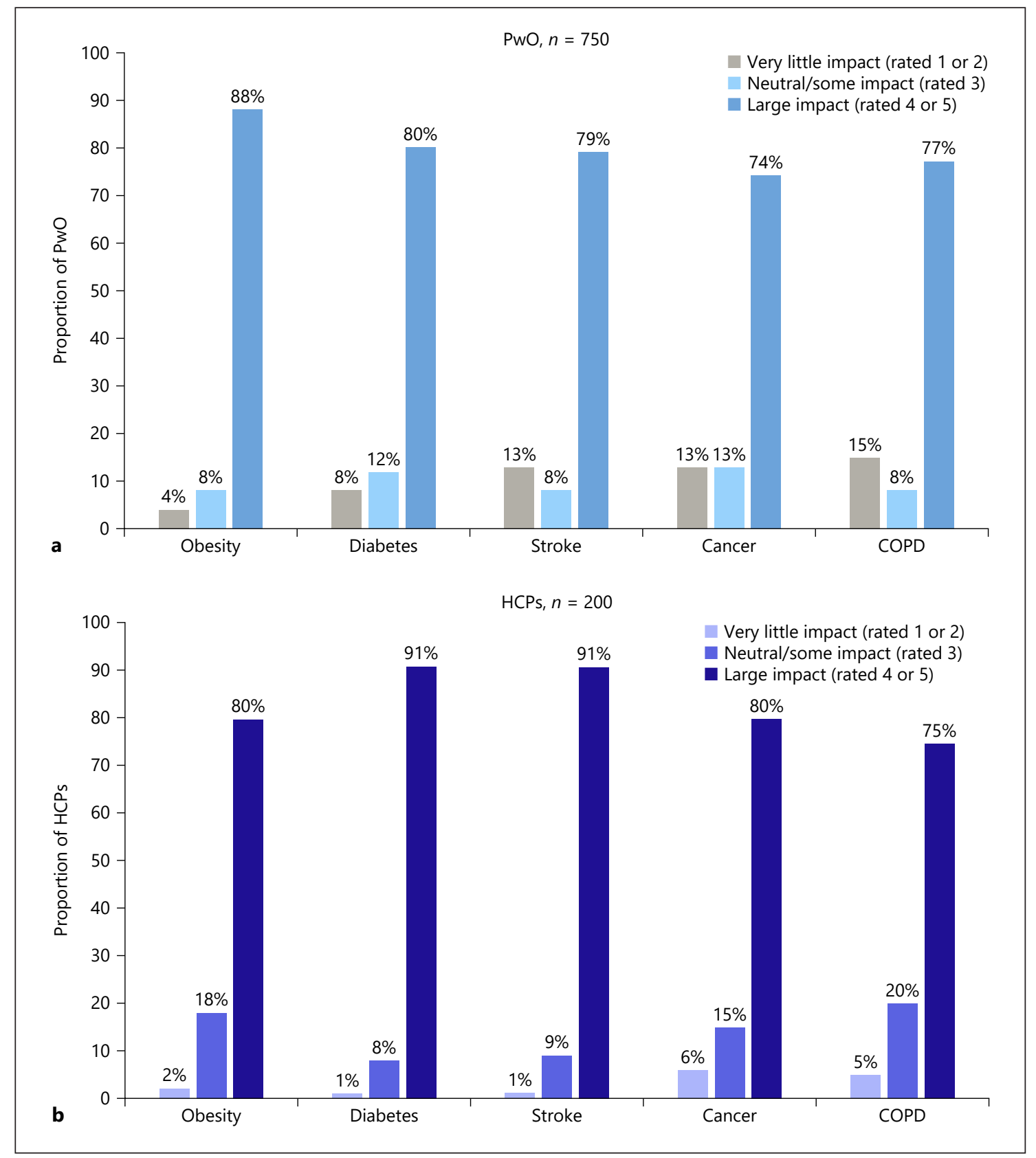

Fig. 2. Perceptions on the impact of health conditions on overall health by $\mathrm{PwO}(\mathbf{a})$ and HCPs (b) in the UAE. Rated on a scale where 1 means "Very little impact" and 5 means "An extreme impact." COPD, chronic obstructive pulmonary disease; HCP, healthcare professional; $\mathrm{PwO}$, people with obesity.

HCPs considered unhealthy eating habits $(80 \%$ of $\mathrm{PwO}$ and $86 \%$ of HCPs) and lack of exercise (70\% of PwO and $93 \%$ of HCPs) as barriers to losing weight, but less than half of $\mathrm{PwO}(40 \%)$ considered genetic factors underlying obesity to be a barrier versus $60 \%$ of HCPs, as shown in Figure 5.

Understanding the Gaps in Obesity Management in the UAE

\section{Weight Management Conversations and Obesity Diagnoses}

In the last 5 years, $78 \%$ of $\mathrm{PwO}$ had a weight management conversation with an HCP. Furthermore, in the last 6 months, $58 \%$ of $\mathrm{PwO}$ had discussed a weight loss plan with their HCP. Of the PwO who talked to their HCP about 


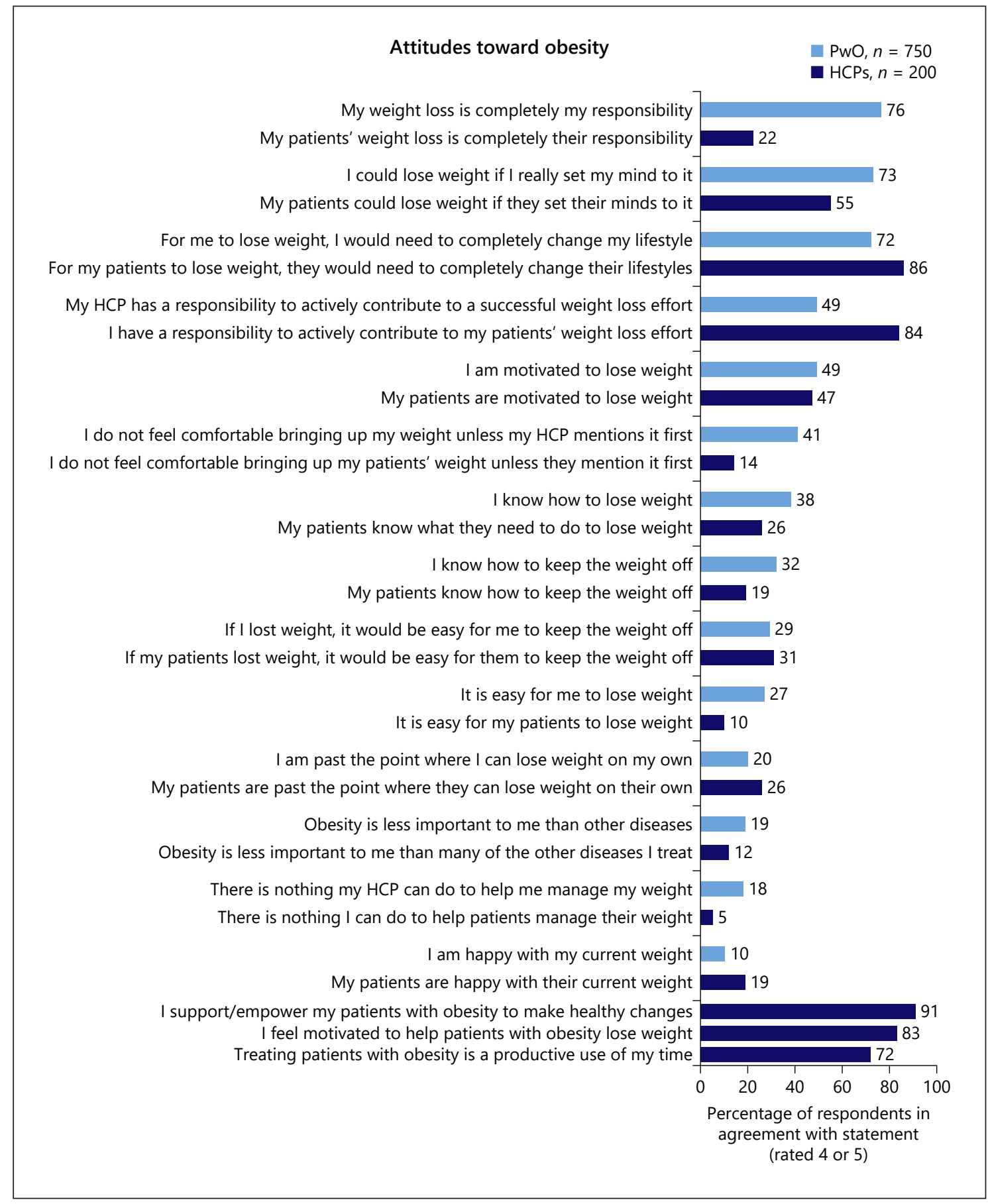

Fig. 3. Attitudes of UAE PwO and HCP regarding obesity. Rated on a scale where 1 means "Do not agree at all" and 5 means "Completely agree." HCP, healthcare professional; $\mathrm{PwO}$, people with obesity.

weight loss in the last 5 years, 39\% found the conversation very or extremely helpful. Moreover, $89 \%$ of $\mathrm{PwO}$ whose $\mathrm{HCP}$ had raised weight management liked that their HCP had mentioned weight during their appointments, and $84 \%$ of the remaining $\mathrm{PwO}$ noted that they would like their $\mathrm{HCP}$ to talk about weight loss during their appointments.

The HCPs initiated weight loss discussions primarily due to the patient's BMI (92\%), and other important rea- 
sons included the presence of existing obesity-related comorbidities (72\%) or if the patient was at risk of developing new/additional obesity-related comorbidities (64\%). Of those $\mathrm{PwO}$ who had discussed their weight with an HCP in the last 5 years, $89 \%$ had been previously diagnosed with obesity (69\% of total PwO). The HCPs provided a diagnosis of obesity $72 \%$ of the time and only $6 \%$ of HCPs refrained from informing the patients of their obesity diagnosis.

\section{Weight Loss Motivators and Methods}

A desire among $\mathrm{PwO}$ of "wanting to be more fit/in better shape" was the main motivator for weight loss (45\%), while HCPs believed the main motivator to be "having general health concerns" (83\%; shown in Fig. 6). Weight loss targets of at least $11 \%$ body weight reduction were set by $94 \%$ of $\mathrm{PwO}$, with an overall mean weight loss target of $23 \%$. Common approaches for weight management discussed between $\mathrm{PwO}$ and HCPs, as reported by $\mathrm{PwO}$, were diets/healthy eating (65\%), exercise (42\%), and meal or exercise tracking (50\%). Methods that $\mathrm{PwO}$ found most effective for managing weight after trying the method were following a specific diet or diet program (86\%) and elimination diets (71\%). The top methods for managing weight recommended by HCPs, as reported by HCPs, included general improvements in activity levels (67\%) and eating habits (66\%). Similar proportions of $\mathrm{PwO}$ and HCPs found prescription weight loss medications $(50 \%$ and $52 \%$, respectively) and bariatric surgery (50\% and $47 \%$, respectively) effective for long-term weight management. Of $\mathrm{PwO}$ who had discussed weight with an $\mathrm{HCP}$ in the last 5 years and who had maintained $\geq 3 \%$ weight loss for the last 3 years, $85 \%$ used recommendations from a wellness/fitness program or a personal trainer, $82 \%$ used recommendations from an $\mathrm{HCP}$, and only $2 \%$ used resources and strategies found on their own.

\section{Barriers to Weight Loss Discussion}

Most $\mathrm{PwO}$ found weight management conversations with their HCPs positive, with $90 \%$ expressing positive types of emotions after such a conversation; $34 \%$ of $\mathrm{PwO}$ felt negative types of emotions and none felt offended. The top reason PwO did not or would not talk to an HCP about their weight was the belief that even if they were able to lose weight they would regain it (34\%), but only $14 \%$ of HCPs agreed with this. The top reasons HCPs provided for not discussing weight loss with their patients was the perception that patients were not interested in losing weight (69\%) or were not motivated to lose weight (66\%), but lack of interest and motivation were reported

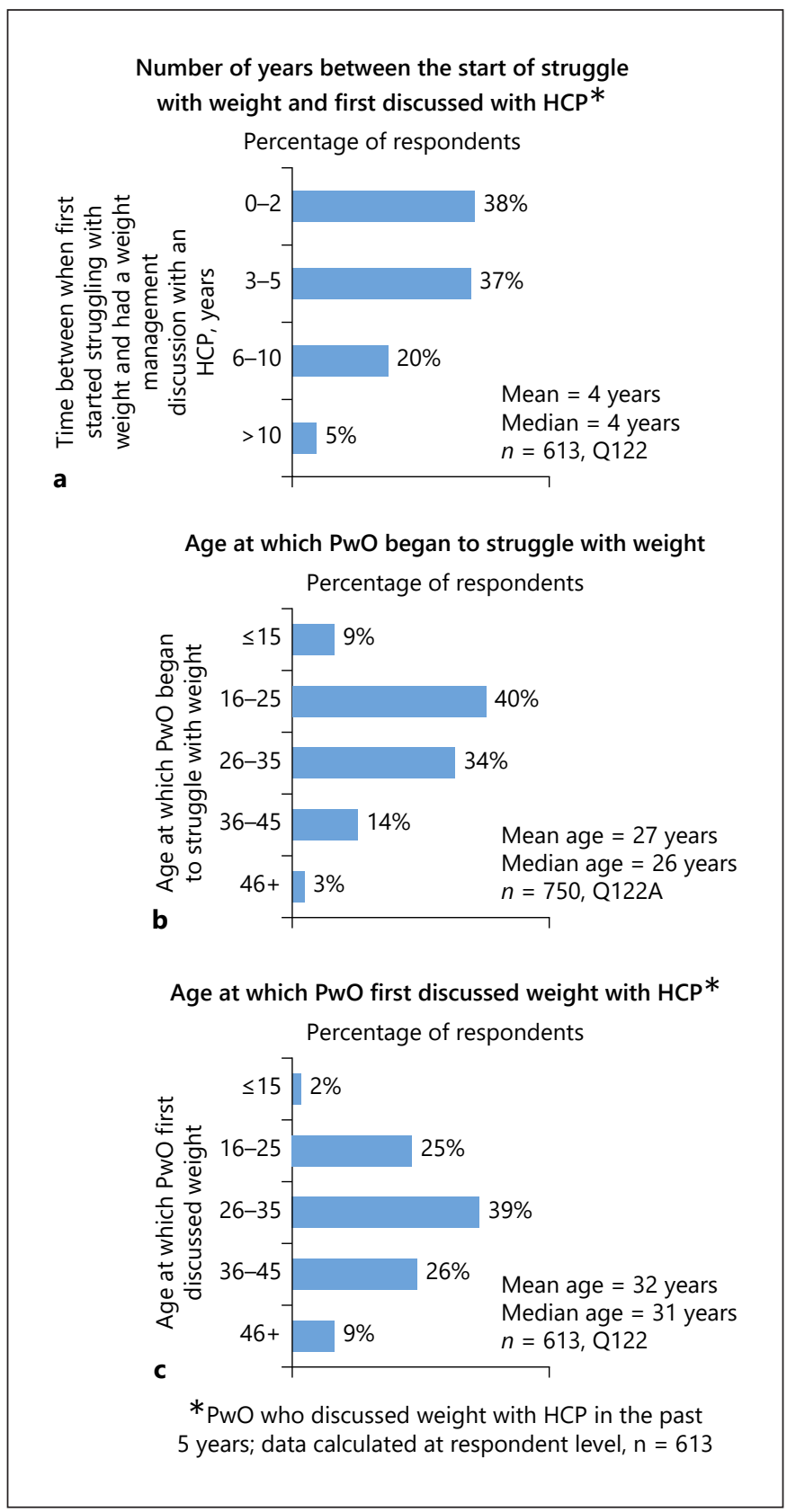

Fig. 4. Time delay between struggling with excess weight and having a weight management discussion with an HCP in the UAE. a Number of years time delay. $\mathbf{b}$ Age when $\mathrm{PwO}$ began struggling with excess weight. c Age when $\mathrm{PwO}$ discussed weight with an $\mathrm{HCP}$ for the first time. HCP, healthcare professional; $\mathrm{PwO}$, people with obesity.

by just $10 \%$ and $30 \%$ of $\mathrm{PwO}$, respectively, as reasons for not discussing weight with an HCP. Some HCPs (44\%) also considered limited appointment time as a barrier to weight loss discussions (shown in Fig. 7). 


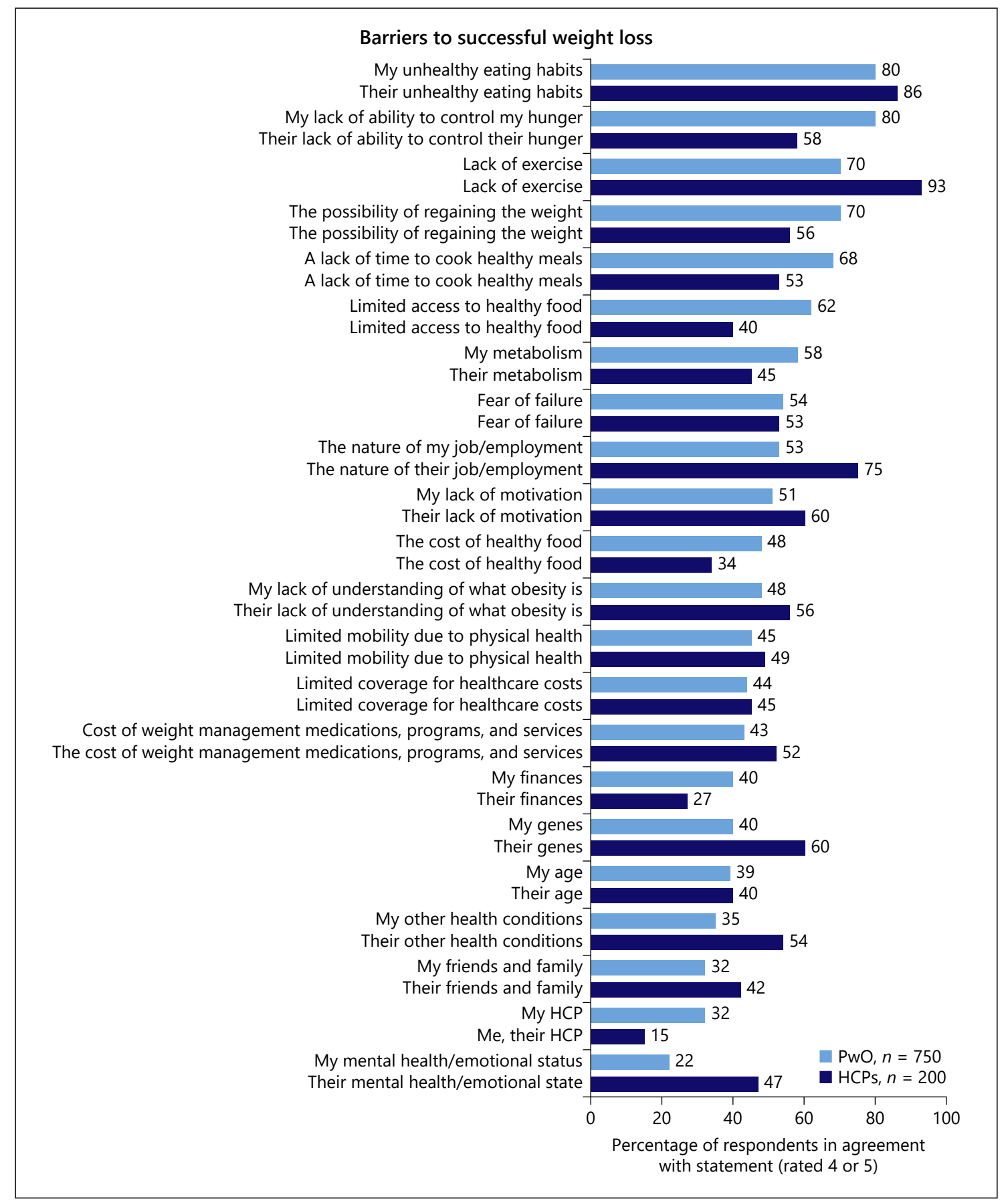

Fig. 5. Main barriers reported for successful weight loss in the UAE. Rated on a scale where 1 means "Do not agree at all" and 5 means "Completely agree." HCP, healthcare professional; PwO, people with obesity.

\section{Scheduling of Follow-Up Appointments}

Many PwO (79\%) who had discussed weight with an $\mathrm{HCP}$ in the last 5 years had a follow-up appointment scheduled after their last visit (62\% of total $\mathrm{PwO}$ ), $98 \%$ of whom reported that they had attended or were planning to attend the appointment. Conversely, HCPs reported scheduling follow-up appointments with only $51 \%$ of their patients with obesity, and under half of HCPs (45\%) said patients attended these appointments always or most of the time. 


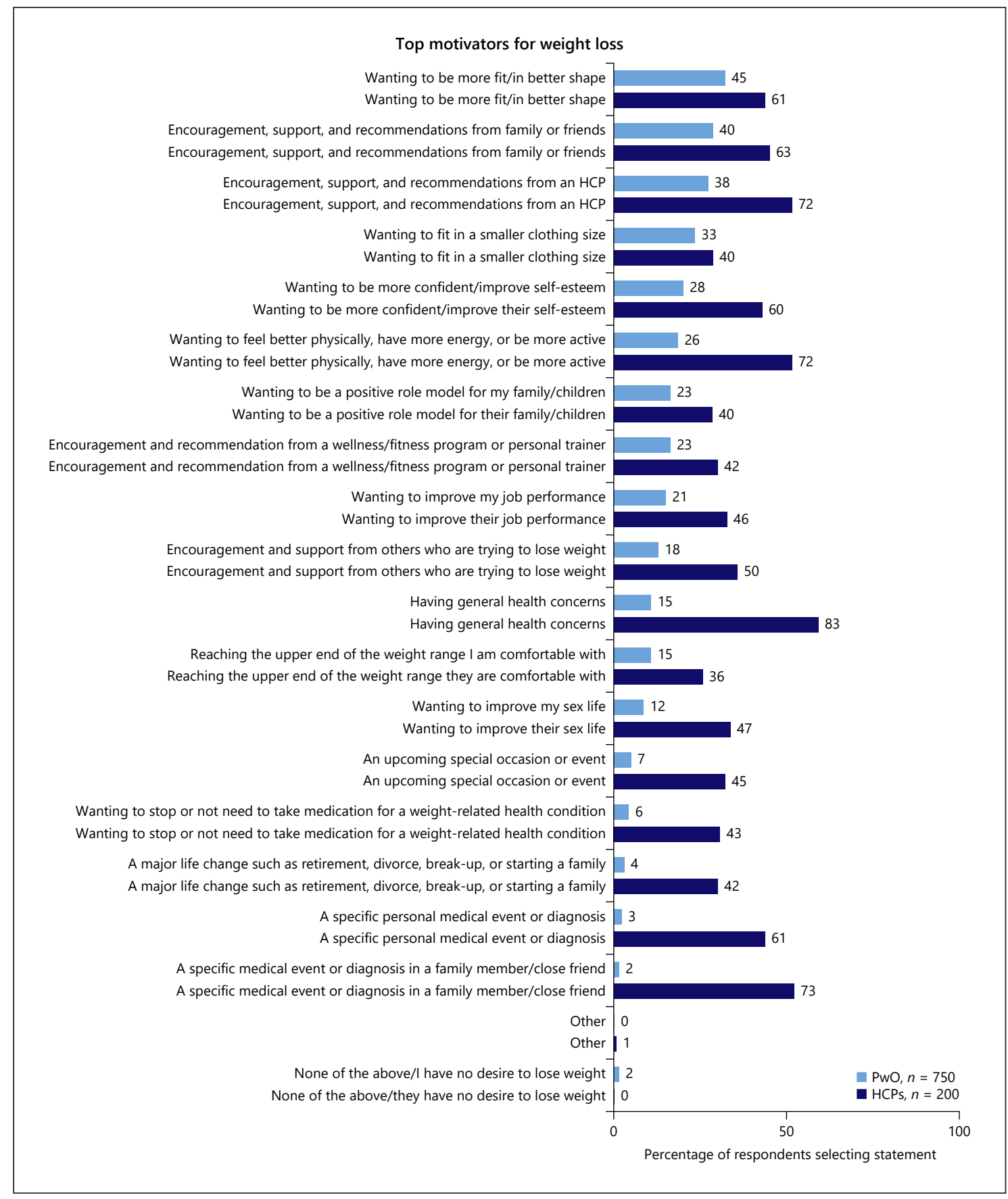

Fig. 6. Top motivators for weight loss in the UAE. PwO selected statements that had motivated them the most to lose weight; HCPs selected statements that, in their experience, motivates people the most to lose weight. HCP, healthcare professional; $\mathrm{PwO}$, people with obesity.

\section{Discussion}

The ACTION-IO study has brought to light several key differences in the attitudes and perceptions of $\mathrm{PwO}$ and HCPs regarding obesity care in the UAE. The major- ity of $\mathrm{PwO}$ and HCPs from the UAE recognized obesity as a chronic disease and believed that a loss of $5-10 \%$ body weight would be extremely beneficial for their overall health. However, more HCPs believed that diabetes and stroke had a larger impact on health than did obesity. 


\section{Reasons for not discussing weight}

Even if I were to lose weight, I would just gain it back Even if the patient were to lose weight, he/she would just gain it back I do not feel motivated to lose weight Patient does not feel motivated to lose weight

I do not believe I am able to lose weight Patient does not believe he/she is able to lose weight
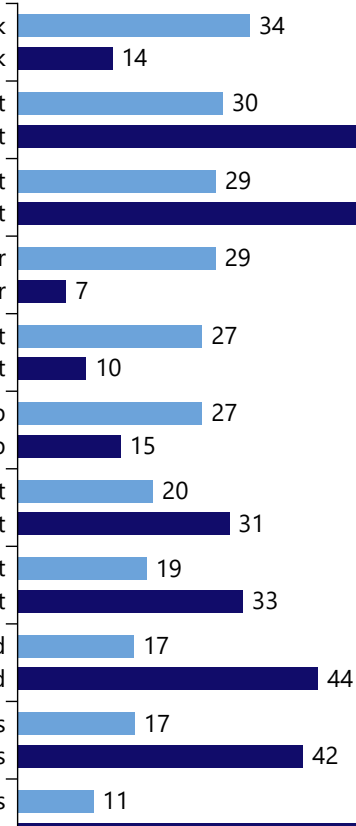

I am in good health and do not have weight-related health problems $\quad 11$

Patient is in good health and does not have weight-related comorbidities

I am not interested in losing weight Patient is not interested in losing weight I do not see my weight as a significant medical issue I do not see weight as a significant medical issue

I have had previous bad experience discussing weight with an HCP I have had previous bad experience discussing weight with a patient

I do not think my HCP is interested in/concerned about my weight I am not interested enough in/concerned enough about patients' weight

There is nothing my HCP can do to help me manage my weight

There is nothing I can do to help patients managing their weight

I do not trust and/or do not have a close relationship with my HCP

I do not trust and/or do not have a close relationship with my patient

My HCP does not have training to provide weight management services I do not have training to provide weight management services

My HCP's office is not set up to treat patients with excess weight/obesity

My office is not set up to treat patients with excess weight/obesity

I do not get financial compensation for treating obesity

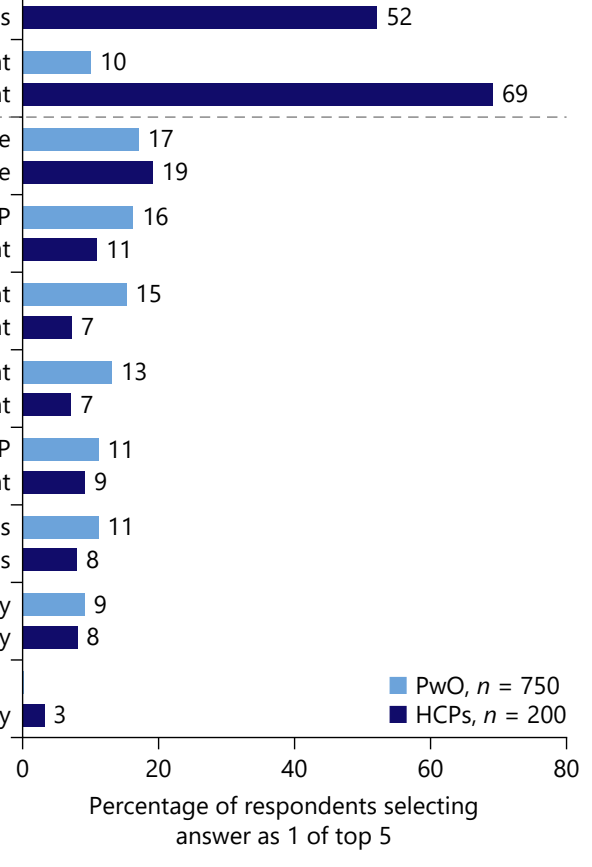

Fig. 7. Reasons for not discussing weight with an HCP (as reported by $\mathrm{PwO}$ ) or with a patient (as reported by HCPs) in the UAE. Responses with at least 10\% difference between PwO and HCPs are shown above the dotted line. HCP, healthcare professional; $\mathrm{PwO}$, people with obesity.

It is important for HCPs to note that both diabetes and stroke are potential comorbidities of obesity and must be taken into consideration when assessing obesity [1-3].
Several differences in perceptions and attitudes among $\mathrm{PwO}$ and HCPs were seen between the UAE data and the other published ACTION-IO cohorts (global [23], Italy [26], Spain [27], South Korea [28], and Japan [29]). The 
mean age of $\mathrm{PwO}$ participating from the UAE was 35 years, while that of PwO from the other ACTION-IO cohorts ranged from 40 to 50 years [23, 26-29]. Similarly, the mean age at which a struggle with weight began among PwO in the UAE was 27 years, while in the other ACTION-IO cohorts it ranged from 33 to 39 years [ACTION-IO study steering committee, personal communication] [27, 28]. A greater percentage of $\mathrm{PwO}$ in UAE considered obesity to be a chronic disease compared with the other ACTION-IO cohorts ( $82 \%$ vs. 58 $78 \%$ ), whereas for HCPs it was lower in comparison $(78 \%$ vs. $81-93 \%)$ [23, 26-29].

Similar to the other published ACTION-IO cohorts (range $80-84 \%$ ), many $\mathrm{PwO}$ in UAE assumed full responsibility for their weight loss (76\%) [23, 26-29]. It is important for HCPs to recognize that $\mathrm{PwO}$ are assuming full responsibility, since this self-blame is a stigmatizing behavior that can contribute to poor mental health and avoidance of exercise in $\mathrm{PwO}$ [15]. This is in contrast to the responses from HCPs across ACTION-IO cohorts; most agreed that they had a role to play in their patients' weight loss success (84\% UAE vs. 76-83\%, except Japan 58\%) [23, 26-29]. Most $\mathrm{PwO}$ and HCPs considered lifestyle-related factors as barriers to weight loss but more HCPs believed in the responsibility of genetic factors. A substantial number of HCPs reported patients not being interested or motivated enough to lose weight as reasons for not discussing weight, which was similar in all ACTION-IO cohorts [23, 26-29]. However, only $10 \%$ of $\mathrm{PwO}$ in the UAE reported disinterest and less than a third of $\mathrm{PwO}$ mentioned motivation as reasons for not discussing weight with their HCP; similarly low percentages were reported by $\mathrm{PwO}$ in other ACTION-IO cohorts [23, 26-29]. These discrepancies in the perceptions about weight management among $\mathrm{PwO}$ and HCPs could be underlying reasons preventing effective weight loss conversations with patients. In the UAE, it took a mean and median of 4 years for $\mathrm{PwO}$ to start a weight loss conversation with an HCP, compared with a mean of 6 years and a median of 3 years globally [23]. It is important to try to further reduce this time gap in the UAE by initiating weight loss conversations earlier, in order to manage the disease of obesity earlier, and thus reduce and prevent the complications of obesity.

Many UAE PwO discussed excess weight or losing weight with their HCP in the last 5 years (78\%), and 58\% subsequently discussed a weight loss plan with their $\mathrm{HCP}$ in the last 6 months. This was higher than the results reported by global $\mathrm{PwO}$ (54\% and $28 \%$, respectively) [ACTION-IO study steering committee, personal communication] [23]. These values may reflect a higher level of awareness among UAE PwO regarding obesity than global PwO.

Among the UAE $\mathrm{PwO}$ who discussed weight loss with an HCP in the last 5 years with a successful $3 \%$ weight loss and maintenance in the last 3 years, $85 \%$ used recommendations from a wellness/fitness program or personal trainer, and only $2 \%$ found weight loss resources and strategies on their own. Conversely, only $20 \%$ of global $\mathrm{PwO}$ used recommendations from a wellness/fitness program or personal trainer, with $44 \%$ finding resources and strategies on their own [ACTION-IO study steering committee, personal communication]. This could be a reflection of the higher socioeconomic status of $\mathrm{PwO}$ in the UAE, who could afford professional weight loss programs without having to search for resources and options alone.

Regarding motivators for weight loss, the UAE PwO considered improving their appearance as important, while HCPs believed general health concerns to be the main motivator for losing weight. The relatively young age of the UAE respondents (mean 35 years) and the lack of comorbidities among a majority of them $(58 \%)$ could potentially explain the selection of improved appearance as the main motivator. Encouragement from HCPs that is tailored to the motivations for this age-group may increase the engagement and likelihood of success in $\mathrm{PwO}$ who attempt weight loss efforts. These data, together with the aforementioned discrepancy in perceptions of interest and motivation as reasons for not discussing weight, highlight the disconnect between the responses from PwO and the perception by HCPs regarding their patients' weight loss concerns and willingness to initiate weight loss conversations. Therefore, by adjusting their perceptions and being more proactive in initiating weight loss conversations, HCPs may play an important role in bridging the gap in obesity management in the UAE. It is important to note that most $\mathrm{PwO}$ reported positive feelings after a weight loss conversation and none felt offended. These insights should further encourage HCPs to hold weight management discussions with patients.

Limitations of the study were the cross-sectional design and descriptive nature as well as the dependence on respondent recall. The self-reported height and weight could lead to underestimation or overestimation of BMI values. Strengths of the study included the large number of respondents in the study and the scientific rigor with which it was designed and implemented, including stratified sampling which provided a cohort highly representative of the general population. 


\section{Conclusions}

Both PwO and HCPs acknowledged obesity as a chronic disease that has a substantial impact on overall health. However, misperceptions between $\mathrm{PwO}$ and HCPs were identified that may be limiting current obesity management in the $\mathrm{UAE}$. The insights into $\mathrm{PwO}$ motivations for weight loss and feelings about weight management conversations with HCPs present an opportunity to enhance the timing and quality of PwO-HCP weight consultations. The results highlighted the prior need for improvements in understanding the perceptions, attitudes, and behaviors that both $\mathrm{PwO}$ and HCPs have toward obesity. Now that misconceptions have been identified, there is an opportunity to improve education concerning the physiological basis and clinical management of obesity and to precipitate effective change to bridge the remaining gaps in obesity care in the UAE.

\section{Acknowledgements}

We thank the participants and the personnel who assisted with the trial.

\section{Statement of Ethics}

The study and survey instruments were approved by the Dubai Healthcare City Authority-Regulation Research Ethics Review Committee on July 11, 2018; no identifying number was provided with the approval. The study was conducted in accordance with the Guidelines for Good Pharmacoepidemiology Practices and with the Declaration of Helsinki. All participants provided electronic informed consent prior to initiation of the survey screening questions.

\section{Conflict of Interest Statement}

R.N. reports financial support from Novo Nordisk to attend an obesity conference during the conduct of the study, and personal (consultancy and speaker) fees from Novo Nordisk outside the submitted work. H.A., Y.A.M., and Z.B.S. are employees of Novo Nordisk, and H.A. owns shares in Novo Nordisk.

E.I., S.A., F.A.A., F.H.A.H., M.F., and T.M.F. report no conflicts of interest.

\section{Funding Sources}

This study was sponsored by Novo Nordisk, which also provided financial support for medical editorial assistance from Cassandra Krone, $\mathrm{PhD}$ of Articulate Science, Ltd.

\section{Author Contributions}

R.N. contributed to the design of the study. All authors participated in interpretation of the data and drafting and revision of the manuscript. All authors reviewed and approved the final, submitted version.

\section{References}

1 Bray GA, Kim KK, Wilding JPH, World Obesity Federation. Obesity: a chronic relapsing progressive disease process. A position statement of the World Obesity Federation. Obes Rev. 2017;18(7):715-23.

2 Must A, Spadano J, Coakley EH, Field AE, Colditz G, Dietz WH. The disease burden associated with overweight and obesity. JAMA. 1999;282(16):1523-9.

3 Guh DP, Zhang W, Bansback N, Amarsi Z, Birmingham CL, Anis AH. The incidence of co-morbidities related to obesity and overweight: a systematic review and meta-analysis. BMC Public Health. 2009;9:88.

4 Kass DA, Duggal P, Cingolani O. Obesity could shift severe COVID-19 disease to younger ages. Lancet. 2020;395(10236):1544-5.

5 Caussy C, Pattou F, Wallet F, Simon C, Chalopin S, Telliam C, et al. Prevalence of obesity among adult inpatients with COVID-19 in France. Lancet Diabetes Endocrinol. 2020; 8(7):562-4.
6 Garg S, Kim L, Whitaker M, O’Halloran A, Cummings C, Holstein R, et al. Hospitalization rates and characteristics of patients hospitalized with laboratory-confirmed coronavirus disease 2019 - COVID-NET, 14 states, March 1-30, 2020. MMWR Morb Mortal Wkly Rep. 2020;69(15):458-64.

7 Lighter J, Phillips M, Hochman S, Sterling S, Johnson D, Francois F, et al. Obesity in patients younger than 60 years is a risk factor for COVID-19 hospital admission. Clin Infect Dis. 2020;71(15):896-7.

8 Olshansky SJ, Passaro DJ, Hershow RC, Layden J, Carnes BA, Brody J, et al. A potential decline in life expectancy in the United States in the 21st century. N Engl J Med. 2005; 352(11):1138-45.

9 Ul-Haq Z, Mackay DF, Fenwick E, Pell JP. Meta-analysis of the association between body mass index and health-related quality of life among adults, assessed by the SF-36. Obesity. 2013;21(3):E322-7.
10 Busutil R, Espallardo O, Torres A, MartínezGaldeano L, Zozaya N, Hidalgo-Vega Á. The impact of obesity on health-related quality of life in Spain. Health Qual Life Outcomes. 2017;15(1):197.

11 Pimenta FB, Bertrand E, Mograbi DC, Shinohara $\mathrm{H}$, Landeira-Fernandez J. The relationship between obesity and quality of life in Brazilian adults. Front Psychol. 2015;6:966.

12 Bray GA, Frühbeck G, Ryan DH, Wilding JP. Management of obesity. Lancet. 2016; 387(10031):1947-56.

13 Ghanemi A, Yoshioka M, St-Amand J. Broken energy homeostasis and obesity pathogenesis: the surrounding concepts. J Clin Med. 2018;7(11):453.

14 Fan Y, Pedersen O. Gut microbiota in human metabolic health and disease. Nat Rev Microbiol. 2021 Jan;19(1):55-71.

15 Rubino F, Puhl RM, Cummings DE, Eckel $\mathrm{RH}$, Ryan DH, Mechanick JI, et al. Joint international consensus statement for ending stigma of obesity. Nat Med. 2020;26(4):485-97. 
16 World Health Organisation. Obesity and overweight factsheet. 2020. Available from: https://www.who.int/en/news-room/factsheets/detail/obesity-and-overweight.

17 Radwan H, Ballout RA, Hasan H, Lessan N, Karavetian M, Rizk R. The epidemiology and economic burden of obesity and related cardiometabolic disorders in the United Arab Emirates: a systematic review and qualitative synthesis. J Obes. 2018;2018:2185942.

18 ALNohair S. Obesity in gulf countries. Int J Health Sci. 2014;8(1):79-83.

19 Central Intelligence Agency. The World FactBook: Country comparison: obesity - adult prevalence rate. 2016. https://www.cia.gov/ library/publications/the-world-factbook/ fields/367rank.html.

20 Kahan SI. Practical strategies for engaging individuals with obesity in primary care. Mayo Clin Proc. 2018;93(3):351-9.

21 Kaplan LM, Golden A, Jinnett K, Kolotkin RL, Kyle TK, Look M, et al. Perceptions of barriers to effective obesity care: results from the national ACTION study. Obesity. 2018;26(1): 61-9.
22 Sharma AM, Bélanger A, Carson V, Krah J, Langlois MF, Lawlor D, et al. Perceptions of barriers to effective obesity management in Canada: results from the ACTION study. Clin Obes. 2019;9(5):e12329.

23 Caterson ID, Alfadda AA, Auerbach P, Coutinho W, Cuevas A, Dicker D, et al. Gaps to bridge: misalignment between perception, reality and actions in obesity. Diabetes Obes Metab. 2019;21(8):1914-24.

24 International Society for Pharmacoepidemiology (ISPE). Guidelines for Good Pharmacoepidemiology Practices (GPP). ISPE; 2020 [updated 2015]. Available from: https://www. pharmacoepi.org/resources/policies/guidelines-08027/.

25 World Medical Association. World Medical Association Declaration of Helsinki: ethical principles for medical research involving human subjects. JAMA. 2013;310(20): $2191-4$
26 Sbraccia P, Busetto L, Santini F, Mancuso M, Nicoziani P, Nicolucci A. Misperceptions and barriers to obesity management: Italian data from the ACTION-IO study. Eat Weight Disord. 2020 May 8. Epub ahead of print.

27 Salvador J, Vilarrasa N, Poyato F, Rubio MÁ. Perceptions, attitudes, and barriers to obesity management in Spain: results from the Spanish cohort of the international ACTION-IO observation study. J Clin Med. 2020;9(9): E2334.

28 Lim S, Oh B, Lee SH, Kim YH, Ha Y, Kang JH. Perceptions, attitudes, behaviors, and barriers to effective obesity care in South Korea: results from the ACTION-IO study. J Obes Metab Syndr. 2020;29(2):133-42.

29 Iwabu M, Yamauchi T, Shimomura I, Eguchi K, Ogawa Y. Perceptions, attitudes and barriers to obesity management: Japanese data from the ACTION-IO study. J Diabetes Investig. 2020 Oct 5. Epub ahead of print. 